\title{
(2) OPEN ACCESS \\ Low hematocrit levels: a risk factor for long-term outcomes in patients requiring prolonged mechanical ventilation after cardiovascular surgery. A retrospective study
}

\author{
Akito Tsukinaga (ㄷ, ', Shunsuke Takaki 다, ${ }^{2}$ Takahiro Mihara, ${ }^{3}$ Kenta Okamura, ${ }^{3}$ \\ Susumu Isoda, ${ }^{4}$ Kiyoyasu Kurahashi, ${ }^{5}$ Takahisa Goto ${ }^{3}$
}

${ }^{1}$ Department of Critical Care Medicine, Yokohama City University Medical Center, Yokohama, Kanagawa, Japan

${ }^{2}$ Department of Critical Care Medicine, Yokohama City University School of Medicine, Yokohama, Kanagawa, Japan ${ }^{3}$ Department of Anesthesiology, Yokohama City University School of Medicine, Yokohama, Kanagawa, Japan ${ }^{4}$ Department of Cardiothoracic Surgery, Yokohama City University Medical Center, Yokohama, Kanagawa, Japan

${ }^{5}$ Department of Anesthesiology and Intensive Care Medicine, International University of Health and Welfare, School of Medicine, Narita, Chiba, Japan

\section{Correspondence to}

Dr Shunsuke Takaki, Critical Care Medicine, Yokohama City University Hospital, Yokohama, Kanagawa 2360004, Japan;

shunty5323@gmail.com

Accepted 7 August 2019 Published Online First 26 September 2019

\section{Check for updates}

(C) American Federation for Medical Research 2020. Re-use permitted under CC BY-NC. No commercial re-use. Published by BMJ.

To cite: Tsukinaga A, Takaki S, Mihara T, et al. J Investig Med 2020;68:392-396.

\section{ABSTRACT}

While low-risk patients who undergo elective surgery can tolerate low hematocrit levels, the benefits of higher hematocrit levels might outweigh the risk of transfusion in high-risk patients. Therefore, this study aimed to evaluate the effects of perioperative hematocrit levels on mortality in patients requiring prolonged mechanical ventilation (PMV) after a cardiovascular surgery. This single-center retrospective cohort study was conducted on 172 patients who underwent cardiovascular surgery with cardiopulmonary bypass or off-pump coronary artery bypass grafting and required PMV for $\geq 72$ hours in the intensive care unit (ICU) from 2008 to 2012 at the Yokohama City University Medical Center in Yokohama, Japan. Patients were classified according to hematocrit levels on ICU admission: high ( $\geq 30 \%)$ and low $(<30 \%)$ groups. Of 172 patients, 86 were included to each of the low-hematocrit and highhematocrit groups, with median hematocrit levels (first to third quartiles) of $27.4 \%(25.4 \%-28.7 \%)$ and $33.0 \%(31.3 \%-35.5 \%)$, respectively. The difference in survival rates was significant between the two groups using the log-rank test (HR 0.55, $95 \% \mathrm{Cl} 0.32$ to $0.95, p=0.033)$. Cox regression analysis revealed that $\geq 30 \%$ increase in hematocrit levels on ICU admission was significantly associated with decreased long-term mortality (HR $0.40,95 \% \mathrm{Cl}$ 0.20 to $0.80, p=0.0095)$. Lower hematocrit levels on ICU admission was a risk factor for increased longterm mortality, and higher hematocrit levels might outweigh the risk of transfusion in patients requiring PMV after a cardiovascular surgery.

\section{INTRODUCTION}

Perioperative anemia is associated with increased mortality and morbidity in patients who underwent cardiovascular surgery. ${ }^{1-5}$ In contrast, transfusion carries several risks $^{6-8}$; thus, prevention of excessive transfusion is the widely accepted consensus. Accordingly, several randomized controlled trials (RCTs) were conducted to examine whether a restrictive threshold of hematocrit levels in red-cell transfusions reduces postoperative morbidity

\section{Significance of this study}

What is already known about this subject?

- Perioperative anemia is associated with increased mortality and morbidity in patients who underwent cardiovascular surgery.

- In contrast, transfusion carries several risks; thus, prevention of excessive transfusion is the widely accepted consensus.

- Low-risk patients who undergo elective surgery can tolerate low hematocrit levels.

What are the new findings?

- A total of 172 patients underwent cardiovascular surgery and required prolonged mechanical ventilation (PMV) for $\geq 72$ hours in the intensive care unit.

- Patients were classified according to hematocrit levels: high $(\geq 30 \%)$ and low $(<30 \%)$ groups.

- Survival rates were significantly higher in the high-hematocrit group.

How might these results change the focus of research or clinical practice?

- The benefits of higher hematocrit levels might outweigh the risk of transfusion in patients requiring PMV after a cardiovascular surgery.

and healthcare costs after a cardiac surgery, as compared with the liberal threshold.

The Transfusion Requirements After Cardiac Surgery (TRACS) is a RCT that examined the mortality and morbidity between the two groups (restrictive (hematocrit <24\%) and liberal (hematocrit $<30 \%$ ) transfusion groups) from the start of surgery until discharge from intensive care unit (ICU) in patients who underwent cardiac surgery with cardiopulmonary bypass. They found that differences in 30-day all-cause mortality and severe morbidity rates were not significant between the two groups. ${ }^{9}$ Murphy et al conducted a multicenter RCT and tested 90-day serious infections or ischemic 
Table 1 Comparison of preoperative patient characteristics between the low-hematocrit and the high-hematocrit groups

\begin{tabular}{|c|c|c|c|}
\hline Characteristic & $\begin{array}{l}\text { Hematocrit <30\% } \\
(n=86)\end{array}$ & $\begin{array}{l}\text { Hematocrit } \geq 30 \% \\
(n=86)\end{array}$ & $P$ value \\
\hline $\begin{array}{l}\text { Gender, ratio of male } \\
(\%)\end{array}$ & $50(58 \%)$ & $59(69 \%)$ & 0.21 \\
\hline Age (years) & $71(63-76)$ & $68.5(61-76)$ & 0.39 \\
\hline Height $(\mathrm{cm})$ & $160(152.5-167)$ & $163(155-168.4)$ & 0.29 \\
\hline Weight (kg) & $60(50-70.8)$ & $63(54.2-70.0)$ & 0.11 \\
\hline Smoking within a year & $38(44 \%)$ & $50(58 \%)$ & 0.093 \\
\hline Diabetes mellitus & $21(24 \%)$ & $21(24 \%)$ & 1 \\
\hline Hyperlipidemia & $23(27 \%)$ & $35(41 \%)$ & 0.076 \\
\hline Renal dialysis & $11(13 \%)$ & $6(7 \%)$ & 0.31 \\
\hline Hypertension & $67(78 \%)$ & $69(80 \%)$ & 0.85 \\
\hline $\begin{array}{l}\text { Chronic respiratory } \\
\text { disease }\end{array}$ & $7(8 \%)$ & $7(8 \%)$ & 1 \\
\hline $\begin{array}{l}\text { History of } \\
\text { cardiovascular } \\
\text { operation }\end{array}$ & $11(13 \%)$ & $16(19 \%)$ & 0.4 \\
\hline History of $\mathrm{PCl}$ & $10(12 \%)$ & $12(14 \%)$ & 0.82 \\
\hline $\begin{array}{l}\text { Consciousness } \\
\text { abnormality within } \\
24 \text { hours }\end{array}$ & $12(14 \%)$ & $6(7 \%)$ & 0.21 \\
\hline $\begin{array}{l}\text { Acute myocardial } \\
\text { infarction }\end{array}$ & $15(17 \%)$ & $17(20 \%)$ & 0.85 \\
\hline Angina pectoris & & & 0.38 \\
\hline Stable & $4(5 \%)$ & $8(9 \%)$ & \\
\hline Unstable & $11(13 \%)$ & $14(16 \%)$ & \\
\hline Cardiogenic shock & $13(15 \%)$ & $9(10 \%)$ & 0.49 \\
\hline $\operatorname{LVEF}(\%)$ & $60(55.5-70)$ & $64(54.3-70)$ & 0.63 \\
\hline Hemoglobin (g/L) & 103 (90 to 115$)$ & 107 (97 to 116) & 0.32 \\
\hline Hematocrit (\%) & $30(27-34)$ & $31(29-34)$ & 0.36 \\
\hline $\begin{array}{l}\text { Preoperative serum } \\
\text { creatinine (mg/dL) }\end{array}$ & $1.18(0.81-1.72)$ & $0.99(0.84-1.35)$ & 0.2 \\
\hline
\end{tabular}

Quantitative data are expressed as medians (first to third IQRs), and categorical data are expressed as frequencies (percentages).

LVEF, left ventricular ejection fraction; $\mathrm{PCl}$, percutaneous coronary intervention.

events between the two groups: restrictive (hemoglobin level $<75 \mathrm{~g} / \mathrm{L}$

$\mathrm{g} / \mathrm{dL}$ ) and liberal (hemoglobin level $<90 \mathrm{~g} / \mathrm{L}$ ) transfusion groups in patients who underwent non-emergency cardiac surgery. ${ }^{10}$ They found that a restrictive transfusion threshold after cardiac surgery was not superior to a liberal threshold with respect to morbidity or healthcare costs, and that the number of deaths in the restrictive-threshold group was higher than that in the liberal-threshold group (4.2\% vs $2.6 \%$; HR $1.64 ; 95 \%$ CI 1.00 to $2.67 ; \mathrm{p}=0.045$ ) in their secondary analysis. The adequate threshold of hematocrit level for transfusion for patients who underwent cardiovascular surgery remains controversial.

These studies have examined short-term outcomes: 30-day or 90-day mortality and morbidity. However, few studies examined the long-term outcome. We might need to investigate not just the short-term outcome but also the long-term outcome to determine the adequate threshold for hematocrit levels for patients who underwent cardiovascular surgery. Moreover, one possible reason for the inconsistencies observed among these trials is the high variability in disease severity among patients who underwent cardiac surgery. For example, their subgroup analysis of TRACS revealed that the restrictive transfusion strategy was associated with more frequent cardiogenic shock events than the liberal transfusion strategy in patients aged $\geq 60$ years. ${ }^{11}$ It is conceivable that low-risk patients who undergo elective surgery might tolerate low hemoglobin levels, whereas the benefits of higher hemoglobin concentration and subsequently improved oxygen supply might outweigh the risk of transfusion in high-risk patients (eg, those with low cardiac output, extensive diseases or who undergo complex surgery).

One clinical index of sickness in patients who underwent cardiac surgery is prolonged mechanical ventilation (PMV), because it is associated with increased early term and midterm mortality. ${ }^{12-16}$ Perioperative low cardiac output and unstable hemodynamics were demonstrated to be associated with PMV. ${ }^{14}$ 17-19 In such patients, compromised oxygen supply to peripheral tissues and vital organs might be compensated by higher hemoglobin concentrations.

This study aimed to identify the association between perioperative anemia and long-term outcomes in patients who require PMV after a cardiovascular surgery.

\section{MATERIALS AND METHODS}

The protocol was registered at the University Hospital Medical Information Network Center (R000032309, UMIN000028228).

Patient data were retrospectively collected from medical records. Consecutive patients who underwent cardiovascular surgery with cardiopulmonary bypass or with off-pump coronary artery bypass grafting (CABG) and who required PMV in the postoperative ICU between 2008 and 2012 were included. Patients who underwent abdominal aortic aneurysm surgery or endovascular stent grafting, those aged $\leq 18$ years and those with insufficient data in their medical record were excluded from the final analysis. In previous studies, the duration of PMV varied between $>24$ hours and 7 days after surgery. ${ }^{12-14}$ 18-20 In $^{18}$ this study, PMV duration was arbitrarily set at $>72$ hours.

Data related to patient characteristics included gender, age, height, body weight and smoking history within the last year, underlying diseases (diabetes mellitus, hyperlipidemia, renal dialysis, hypertension and chronic respiratory disease), medical history (cardiovascular surgery and coronary intervention), preoperative state (abnormal consciousness within the last 24 hours, acute myocardial infarction, angina pectoris, cardiogenic shock, hemoglobin, hematocrit, serum creatinine and left ventricular ejection fraction (LVEF)), operative and anesthetic information (operative time, emergency (vs elective surgery), type of surgery, duration of cardiopulmonary bypass, amount of bleeding, amount of transfusion and amount of urine output) and postoperative information (hemoglobin and hematocrit levels on ICU admission, maximum serum creatinine level postoperatively, duration of mechanical ventilation, reintubation, reoperation for bleeding, complications, length of ICU stay, mortality, follow-up duration and status at the end of follow-up). Postoperative mortality was categorized into 30 days, 1 year and long-term with >1-year follow-up. Quantitative data were expressed as medians (first to third quartiles), and categorical data as frequencies (percentages). Patients who required PMV after the cardiovascular surgery were 
Table 2 Comparison of intraoperative and postoperative outcomes of patients between the low-hematocrit and the high-hematocrit groups

\begin{tabular}{|c|c|c|c|}
\hline Characteristic & $\begin{array}{l}\text { Hematocrit }<30 \% \\
(n=86)\end{array}$ & $\begin{array}{l}\text { Hematocrit } \geq 30 \% \\
(n=86)\end{array}$ & $P$ value \\
\hline Operation time (min) & $486(396-611)$ & $444(341-569)$ & 0.25 \\
\hline Urgency & & & 1 \\
\hline Elective & $39(45 \%)$ & $40(47 \%)$ & \\
\hline Emergent & $47(55 \%)$ & $46(54 \%)$ & \\
\hline Types of procedure & & & 0.016 \\
\hline CABG & $7(8 \%)$ & $18(21 \%)$ & \\
\hline Valve surgery & $20(23 \%)$ & $8(9 \%)$ & \\
\hline$C A B G$ and valve surgery & $9(11 \%)$ & $5(6 \%)$ & \\
\hline Aortic surgery & $48(56 \%)$ & $51(59 \%)$ & \\
\hline Others & $2(2 \%)$ & $4(5 \%)$ & \\
\hline Duration of cardiopulmonary bypass (min) & $223(181-278)$ & $219(156-283)$ & 0.43 \\
\hline Amount of bleeding during surgery $(\mathrm{mL})$ & $2000(1386-2728)$ & $1920(1321-2958)$ & 0.92 \\
\hline Amount of transfusion during surgery $(\mathrm{mL})$ & $3645(2598-5295)$ & $3450(2128-5380)$ & 0.58 \\
\hline Amount of urine output during surgery $(\mathrm{mL})$ & $1270(655-1903)$ & $1340(636-2183)$ & 0.34 \\
\hline Hemoglobin on ICU admission (g/L) & $8.8(8.2-9.3)$ & $10.7(10.1-11.5)$ & \\
\hline Hematocrit on ICU admission (g/dL) & $27.4(25.4-28.7)$ & $33.0(31.3-35.5)$ & \\
\hline Maximum serum creatinine after operation $(\mathrm{mg} / \mathrm{dL})$ & $2.00(1.10-3.91)$ & $1.63(1.16-2.80)$ & 0.82 \\
\hline Duration of mechanical ventilation (hours) & $192(120-360)$ & $144(120-258)$ & 0.13 \\
\hline Reintubation & $11(13 \%)$ & $12(14 \%)$ & 1 \\
\hline Reoperation for bleeding & $18(21 \%)$ & $6(7 \%)$ & 0.014 \\
\hline \multicolumn{4}{|l|}{ Complications } \\
\hline Stroke & $17(20 \%)$ & $9(11 \%)$ & 0.14 \\
\hline Paraparesis & $4(5 \%)$ & $3(4 \%)$ & 1 \\
\hline Renal failure & $23(27 \%)$ & $24(28 \%)$ & 1 \\
\hline Dialysis & $14(16 \%)$ & $15(17 \%)$ & 1 \\
\hline Myocardiac infarction & $3(4 \%)$ & $3(4 \%)$ & 1 \\
\hline Heart block requiring pacemaker implantation & $2(2 \%)$ & $3(4 \%)$ & 1 \\
\hline Arrest & $6(7 \%)$ & $3(4 \%)$ & 0.5 \\
\hline Tamponade & $8(10 \%)$ & $5(6 \%)$ & 0.4 \\
\hline Atrial fibrillation & $32(37 \%)$ & $24(28 \%)$ & 0.26 \\
\hline Mediastinitis & $5(6 \%)$ & $1(1 \%)$ & 0.21 \\
\hline Pulmonary embolism & $1(1 \%)$ & $0(0 \%)$ & 1 \\
\hline Pneumonia & $26(30 \%)$ & $21(24 \%)$ & 0.49 \\
\hline Length of ICU stay (days) & $10.5(6.3-20.5)$ & $9.5(5.3-14)$ & 0.18 \\
\hline Thirty-day mortality & $5(6 \%)$ & $3(4 \%)$ & 0.72 \\
\hline One-year mortality & $17(22 \%)$ & $13(18 \%)$ & 0.54 \\
\hline
\end{tabular}

Quantitative data are expressed as medians (first to third IQRs), and categorical data are expressed as frequencies (percentages).

CABG, coronary artery bypass grafting; ICU, intensive care unit.

divided according to their hematocrit values on ICU admission: high $(\geq 30 \%)$ and low $(<30 \%)$.

The two groups were compared using the Student's t-test or the Mann-Whitney $U$ test for continuous variables and the Fisher's exact test for percentages, as appropriate. Survival rate was evaluated using the Kaplan-Meier method and compared using the log-rank test. The Cox regression model was used to evaluate the effects of hematocrit on survival rate. The following factors were examined as explanatory variables: age, gender, smoking, hypertension, preoperative serum creatinine level, preoperative dialysis, preoperative hematocrit level, LVEF, surgery type, amount of bleeding, amount of transfusion, hematocrit level on ICU admission, length of ICU stay, duration of mechanical ventilation, operative time, perfusion time, reoperation for bleeding, stroke as a complication and reintubation.
All tested parameters were examined for multicollinearity. If a correlation was observed between any pair of parameters, one of them was excluded from the Cox regression model. A forward stepwise selection procedure was used to develop the final regression model, with model selection at the lowest value of Akaike's information criterion at each step. ${ }^{21}$ For two-tailed tests, a $p$ value of $<0.05$ was considered to be statistically significant. Statistical analyses were performed using Prism 6 for Mac OS X 6.9b (GraphPad Software, San Diego, California, USA) and R V.2.13.0 statistical software (R Foundation for Statistical Computing, Vienna, Austria).

\section{RESULTS}

A total of 172 patients were included in this 5 -year retrospective study. There were coincidentally 86 patients each in the 


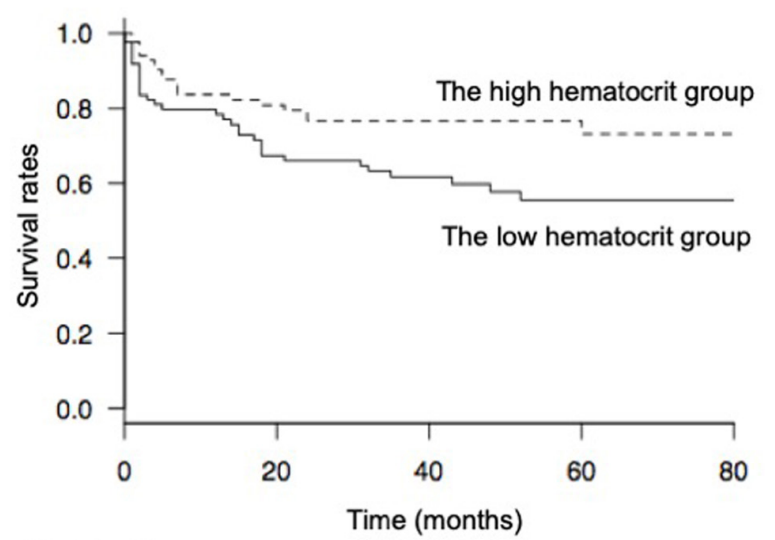

No. at risk

$\begin{array}{lllll}86 & 49 & 33 & 22 & 7 \\ 86 & 58 & 41 & 22 & 8\end{array}$

Figure 1 Kaplan-Meier curves for OS between the two groups by hematocrit levels on ICU admission. Kaplan-Meier curves showing that there was a significant difference in the survival rates between the high hematocrit $(\geq 30 \%)$ and the low hematocrit $(<30 \%)$ groups (HR $0.55,95 \% \mathrm{Cl} 0.32$ to $0.95, \mathrm{p}=0.033$ by the log-rank test). ICU, intensive care unit; OS, overall survival.

low-hematocrit and high-hematocrit groups. Comparison of preoperative patient characteristics between the two groups is shown in table 1 . No statistically significant differences were observed in any of the parameters, including preoperative LVEF and hemoglobin concentrations.

Comparison of the perioperative outcomes between the two groups are shown in table 2. Specifically, types of procedure were different between the two groups $(p=0.016)$. More patients in the high-hematocrit group underwent CABG, whereas more patients in the low-hematocrit group underwent valve or combined CABG and valve surgery. Notably, more than half of the patients in both groups underwent aortic surgery. The high-hematocrit group also had significantly less number of reoperations for bleeding ( $\mathrm{n}=18(21 \%)$ vs $\mathrm{n}=6(7 \%), \mathrm{p}=0.014)$. The median hematocrit level on ICU admission (first to third quartiles) was $27.4 \%(25.4 \%-28.7 \%)$ in the low-hematocrit group and $33.0 \%(31.3 \%-35.5 \%)$ in the high-hematocrit group. Differences in the length of ICU stay (10.5 vs 9.5 days, $\mathrm{p}=0.18)$, 30 -day mortality $(\mathrm{n}=5(6 \%)$ vs $\mathrm{n}=3(4 \%), \mathrm{p}=0.72)$ and 1 -year mortality $(n=17(22 \%)$ vs $n=13(18 \%), p=0.544)$ were not significant between the two groups according to the univariate analysis.

Figure 1 shows the Kaplan-Meier curves. The duration of follow-up was long-term, with median (first to third quartiles) of 37.5 (7-59.25) months in the high-hematocrit group and 33.5 (4-59.8) months in the low-hematocrit group. The survival rate was significantly higher in the high-hematocrit group than in the low-hematocrit group (HR 0.55, 95\% CI 0.32 to $0.95, \mathrm{p}=0.033$ ). Table 3 shows the results of Cox proportional hazards model. Specifically, the amount of bleeding, preoperative dialysis, perfusion time and duration of mechanical ventilation were excluded because multicollinearity was proven between the amount of transfusion and bleeding, preoperative serum creatinine and preoperative dialysis, operation and perfusion time and length of ICU stay
Table 3 Cox regression analysis for long-term mortality

\begin{tabular}{llll}
\hline Factor & HR & $\mathbf{9 5 \%} \mathbf{C l}$ & P value \\
\hline Age (10years) & 1.43 & 1.03 to 1.98 & 0.031 \\
\hline Gender (female) & 0.36 & 0.15 to 0.87 & 0.024 \\
Smoking within a year & 1.75 & 0.80 to 3.84 & 0.16 \\
\hline Hypertension & 0.54 & 0.27 to 1.08 & 0.08 \\
\hline LVEF (10\%) & 0.59 & 0.46 to 0.76 & $<0.001$ \\
\hline Types of procedure & 1.26 & 0.92 to 1.73 & 0.16 \\
\hline Amount of transfusion $(1000 \mathrm{~mL})$ & 1.08 & 0.98 to 1.18 & 0.11 \\
\hline Hematocrit on ICU admission $(\geq 30 \%)$ & 0.40 & 0.20 to 0.80 & 0.01 \\
\hline Length of ICU stay (day) & 1.05 & 1.03 to 1.07 & $<0.001$ \\
\hline
\end{tabular}

ICU, intensive care unit; LVEF, left ventricular ejection fraction.

and mechanical ventilation. Hematocrit levels on ICU admission were independently associated with long-term mortality (HR $0.40,95 \%$ CI 0.20 to $0.80, p=0.0095$, table 3 ). Other factors that were independently associated with long-term mortality were age (every 10 years, HR 1.43, 95\% CI 1.03 to $1.98, \mathrm{p}=0.031$ ), gender (female, HR $0.36,95 \% \mathrm{CI} 0.15$ to $0.87, \mathrm{p}=0.024)$, LVEF (10\%, HR $0.59,95 \%$ CI 0.46 to 0.76 , $\mathrm{p}<0.001)$ and length of ICU stay (HR 1.05, 95\% CI 1.03 to 1.07, $\mathrm{p}<0.001$, table 3).

\section{DISCUSSION}

The results of this single-center retrospective study including 172 patients showed that lower hematocrit levels on ICU admission were associated with increased long-term mortality in patients who required PMV.

We followed up patients on median (first to third quartiles) duration of 37.5 (7-59.25) months in the high-hematocrit group and 33.5 (4-59.8) months in the low-hematocrit group. Only a few studies conducted the follow-up as longer time as the present study.

Observational studies have declared that perioperative anemia and transfusion were independent risk factors for increased morbidity and mortality. ${ }^{1-8}$ Therefore, several RCTs were conducted to examine which threshold of hematocrit level for transfusion is adequate in patients who underwent cardiovascular surgery. ${ }^{9} 10$ However, they failed to convincingly determine it. Anemia was significantly associated with short-term outcome and long-term outcome according to the present study. If anemia may affect the long-term outcome, RCTs should be conducted to examine which threshold of hematocrit level for transfusion is adequate for the long-term outcome.

Patients who required PMV after a cardiovascular surgery were included. Because they might be at a high risk of decreased oxygen supply, higher hematocrit levels and so improved oxygen supply might outweigh the risk of transfusion; therefore, this study demonstrated that lower hematocrit levels on ICU admission were associated with higher long-term mortality.

Several studies showed that preoperative anemia alone was an important cause of morbidity and mortality in cardiac surgery. ${ }^{22-24}$ However, preoperative anemia was not significantly associated with long-term mortality in the present study, probably due to the small sample size. Preoperative treatment with iron and erythropoietin for patients with anemia was found to be effective in several studies. ${ }^{25} 26$ 
Preoperative transfusion to manage anemia might outweigh the risk of transfusion and improve postoperative outcomes in critically ill patients.

This study has several limitations. First, lower hematocrit levels on ICU admission might occur due to continuous bleeding postoperatively. This is reflected in a significantly increased number of reoperations for bleeding in patients with low hematocrit levels, as compared with those with high hematocrit levels. Even after including reoperation for bleeding as an independent variable in the Cox regression analysis for long-term mortality, hematocrit levels on ICU admission remained to be associated with long-term morality. Second, data on hematocrit values during surgery or ICU stay were not included in the analysis. In some patients, hematocrit values during these time points were different from those measured on ICU admission. Third, this study included different types of cardiac surgery. Finally, because this was a retrospective cohort study, biases may be introduced due to variations in surgeons, clinicians and nursing personnel. Therefore, the causal relationship between the hematocrit levels on ICU admission and mortality was not elucidated. Lower hematocrit levels on ICU admission have been assumed to lead to critical anemia in patients who required PMV after a cardiovascular surgery, resulting in increased mortality. Although several studies already examined the association between anemia or transfusion and mortality, only a few conducted a follow-up for a sufficiently long duration as in this study.

Our retrospective analysis suggests that lower hematocrit level on ICU admission was a risk factor for increased longterm mortality in patients who required PMV after a cardiovascular surgery. The benefits of higher hematocrit levels in reducing long-term mortality in patients who underwent cardiovascular surgery remained to be elucidated. RCTs to examine which hematocrit level required transfusion for longterm mortality are necessary to confirm our findings.

Contributors ST, SI, KK and TG contributed to the conception and design for the work. KO contributed to the data acquisition for the work. TM contributed to the data analysis for the work.

Funding The authors have not declared a specific grant for this research from any funding agency in the public, commercial or not-for-profit sectors.

Competing interests None declared.

Patient consent for publication Not required.

Ethics approval This study was conducted at the Yokohama City University Medical Center and approved by their institutional review board (approval number: D1601003; date: 7 May 2016).

Provenance and peer review Not commissioned; externally peer reviewed.

Open access This is an open access article distributed in accordance with the Creative Commons Attribution Non Commercial (CC BY-NC 4.0) license, which permits others to distribute, remix, adapt, build upon this work noncommercially, and license their derivative works on different terms, provided the original work is properly cited, an indication of whether changes were made, and the use is non-commercial. See: http://creativecommons.org/ licenses/by-nc/4.0/.

\section{ORCID iDs}

Akito Tsukinaga http://orcid.org/0000-0002-3259-9893

Shunsuke Takaki http://orcid.org/0000-0003-4526-9014

\section{REFERENCES}

1 Kim CJ, Connell H, McGeorge AD, et al. Prevalence of preoperative anaemia in patients having first-time cardiac surgery and its impact on clinical outcome. A retrospective observational study. Perfusion 2015;30:277-83.

2 Fang WC, Helm RE, Krieger KH, et al. Impact of minimum hematocrit during cardiopulmonary bypass on mortality in patients undergoing coronary artery surgery. Circulation 1997;96:II-194-199.

3 Bahrainwala ZS, Grega MA, Hogue CW, et al. Intraoperative hemoglobin levels and transfusion independently predict stroke after cardiac operations. Ann Thorac Surg 2011;91:1113-8.

4 Habib RH, Zacharias A, Schwann TA, et al. Role of hemodilutional anemia and transfusion during cardiopulmonary bypass in renal injury after coronary revascularization: implications on operative outcome. Crit Care Med 2005;33:1749-56.

5 Westenbrink BD, Kleijn L, de Boer RA, et al. Sustained postoperative anaemia is associated with an impaired outcome after coronary artery bypass graft surgery: insights from the IMAGINE trial. Heart 2011;97:1590-6.

6 Koch CG, Li L, Duncan Al, et al. Transfusion in coronary artery bypass grafting is associated with reduced long-term survival. Ann Thorac Surg 2006;81:1650-7.

7 Engoren MC, Habib RH, Zacharias A, et al. Effect of blood transfusion on longterm survival after cardiac operation. Ann Thorac Surg 2002;74:1180-6.

8 Leal-Noval SR, Rincón-Ferrari MD, García-Curiel A, et al. Transfusion of blood components and postoperative infection in patients undergoing cardiac surgery. Chest 2001;119:1461-8.

9 Hajjar LA, Vincent JL, Galas FR, et al. Transfusion requirements after cardiac surgery: the TRACS randomized controlled trial. JAMA 2010;304:1559-67.

10 Murphy GJ, Pike K, Rogers CA, et al. Liberal or restrictive transfusion after cardiac surgery. N Engl J Med 2015;372:997-1008.

11 Nakamura RE, Vincent JL, Fukushima JT, et al. A liberal strategy of red blood cell transfusion reduces cardiogenic shock in elderly patients undergoing cardiac surgery. J Thorac Cardiovasc Surg 2015;150:1314-20.

12 Saleh HZ, Shaw M, Al-Rawi 0, et al. Outcomes and predictors of prolonged ventilation in patients undergoing elective coronary surgery. Interact Cardiovasc Thorac Surg 2012;15:51-6.

13 Trouillet JL, Combes A, Vaissier E, et al. Prolonged mechanical ventilation after cardiac surgery: outcome and predictors. J Thorac Cardiovasc Surg 2009;138:948-53.

14 Pappalardo F, Franco A, Landoni G, et al. Long-term outcome and quality of life of patients requiring prolonged mechanical ventilation after cardiac surgery. Eur J Cardiothorac Surg 2004;25:548-52.

15 Van Caenegem O, Jacquet LM, Goenen M. Outcome of cardiac surgery patients with complicated intensive care unit stay. Curr Opin Crit Care 2002;8:404-10.

16 Chalmers J, Mediratta N, MCShane J, et al. The long-term effects of developing renal failure post-coronary artery bypass surgery, in patients with normal preoperative renal function. Eur J Cardiothorac Surg 2013;43:555-9.

17 Filsoufi F, Rahmanian PB, Castillo JG, et al. Predictors and early and late outcomes of respiratory failure in contemporary cardiac surgery. Chest 2008;133:713-21

18 Légaré JF, Hirsch GM, Buth KJ, et al. Preoperative prediction of prolonged mechanical ventilation following coronary artery bypass grafting. Eur J Cardiothorac Surg 2001;20:930-6.

19 Murthy SC, Arroliga AC, Walts PA, et al. Ventilatory dependency after cardiovascular surgery. J Thorac Cardiovasc Surg 2007;134:484-90.

20 Spivack SD, Shinozaki T, Albertini JJ, et al. Preoperative prediction of postoperative respiratory outcome. Coronary artery bypass grafting. Chest 1996;109:1222-30.

21 Akaike H. A new look at the statistical model identification. IEEE Trans Automat Contr 1974;19:716-23.

22 Kulier A, Levin J, Moser R, et al. Impact of preoperative anemia on outcome in patients undergoing coronary artery bypass graft surgery. Circulation 2007;116:471-9.

23 Jabagi H, Boodhwani M, Tran DT, et al. The Effect of Preoperative Anemia on Patients Undergoing Cardiac Surgery: A Propensity-Matched Analysis. Semin Thorac Cardiovasc Surg 2019;31:157-63.

24 Karkouti K, Wijeysundera DN, Beattie WS. Reducing Bleeding in Cardiac Surgery (RBC) Investigators. Risk associated with preoperative anemia in cardiac surgery: a multicenter cohort study. Circulation 2008;117:478-84.

25 Cladellas M, Farré N, Comín-Colet J, et al. Effects of preoperative intravenous erythropoietin plus iron on outcome in anemic patients after cardiac valve replacement. Am J Cardiol 2012;110:1021-6.

26 Spahn DR, Schoenrath F, Spahn GH, et al. Effect of ultra-short-term treatment of patients with iron deficiency or anaemia undergoing cardiac surgery: a prospective randomised trial. Lancet 2019;393:2201-12. 